\title{
BMJ Open Using institutional entrepreneurship to understand the role of innovation teams in healthcare: a longitudinal qualitative study
}

\author{
Angela Melder (D) , ${ }^{1}$ Ian Mcloughlin, ${ }^{2}$ Tracy Robinson, ${ }^{3}$ Rick ledema (D) , ${ }^{4}$ \\ Helena J Teede ${ }^{1}$
}

To cite: Melder A, Mcloughlin I, Robinson T, et al. Using institutional entrepreneurship to understand the role of innovation teams in healthcare: a longitudinal qualitative study. BMJ Open 2021;11:e046750. doi:10.1136/ bmjopen-2020-046750

- Prepublication history and additional supplemental material for this paper are available online. To view these files, please visit the journal online (http://dx.doi.org/10.1136/ bmjopen-2020-046750).

Received 10 November 2020 Accepted 21 August 2021

\section{Check for updates}

(c) Author(s) (or their employer(s)) 2021. Re-use permitted under CC BY-NC. No commercial re-use. See rights and permissions. Published by BMJ.

${ }^{1}$ Monash Centre for Health Research and Implementation, School of Public Health and Preventive Medicine, Faculty of Medicine Nursing and Health Sciences, Monash University, Clayton, Victoria, Australia ${ }^{2}$ Monash Business School, Monash University, Clayton, Victoria, Australia

${ }^{3}$ School of Nursing, Paramedicine and Healthcare Science, Charles Sturt University, Albury, New South Wales, Australia

${ }^{4}$ Centre for Team Based Practice \& Learning in Health Care, King's College, London, UK

Correspondence to

Dr Helena J Teede;

Helena.Teede@monash.edu

\section{ABSTRACT}

Objectives We draw on institutional theory to explore the roles and actions of innovation teams and how this influences their behaviour and capabilities as 'institutional entrepreneurs (IEs)', in particular the extent to which they are both 'willing' and 'able' to facilitate transformational change in healthcare through service redesign.

Design A longitudinal qualitative study that applied a 'researcher in residence' as an ethnographic approach. Setting The development and implementation of two innovation projects within a single public hospital setting in an Australian state jurisdiction.

Participants Two innovation teams, with members including senior research fellows, PhD scholars and frontline clinicians (19 participants and 47 interviews).

Results Despite being from the same hospital, the two innovation teams occupied contrasting subject positions with one facilitating transformational improvements in service delivery, while the other sought more conservative improvements. Cast as 'IEs' we show how one team took steps to build legitimacy for their interventions enabling spread and scale in improvements and how, in the other case, failure to build legitimacy resulted in unintended consequences which undermined the sustainability of the improvements achieved.

Conclusions Adopting an institutional approach provided insight into the 'willingness' and 'ability' to facilitate transformational change in healthcare through service redesign. The manner in which innovation teams operate from different subject positions influences the structural and normative legitimacy afforded to their activities. Specifically, we observed that those with the most power (organisational or professional) to bring about transformational change can be the least willing to do so in ways which challenge current practice. Those most willing to challenge the status quo (more peripheral organisation members or professionals) can be least able to deliver transformation. Better understanding of these insights can inform healthcare leaders in supporting innovation team efforts, considering their subject position.

\section{INTRODUCTION}

Institutional entrepreneurship (IEP) is drawn from the application of institutional theory in management and organisation
Strengths and limitations of this study

- In-depth, longitudinal examination of the behaviour and organisational position of healthcare innovation teams through the theoretical lens of institutional entrepreneurship.

- We use an innovative 'researcher in residence' approach to understand the complex roles of innovation teams in a real-world setting.

- We acknowledge potential limitations of this approach but emphasise the additional insights provided by the lead researcher's insider status into normally overlooked deeper and less-observable aspects of the context in which service innovation in healthcare takes place.

- We provide practical learning and actionable knowledge drawn from diverse disciplines of management and organisational studies, health services management, implementation science and healthcare improvement.

studies. It addresses the so-called 'paradox of embedded agency' by seeking to explain why those in positions which confer higher status and organisational power may be the least willing to challenge the status quo, while those with lower status and less power may be the least able, but most willing to bring about transformational change. This predicament commonly faces healthcare innovation teams, who often find themselves charged with transforming well-established ways of working that are embedded in organisational hierarchies and professional practice. They often find themselves ill-equipped to deal with difficulties in the implementation and sustainability of interventions, despite increasing external and internal pressures for change. ${ }^{12}$

The potential of IEP to more clearly reveal the deeper and less observable organisational aspects of healthcare innovation in relation to power and its legitimate use is increasingly recognised in this field of research. ${ }^{13-5}$ 
Hitherto researchers have focused on the role of individual institutional entrepreneurs (IEs). Here, we aimed to focus on the collective role of IEs, in the form of innovation teams. We draw on institutional theory and specifically the concept of IEP $^{3}$ to explore how innovation teams across their behaviour and capabilities facilitate transformational change in healthcare through service redesign. To achieve this, we aimed to investigate the roles and actions of two front-line IE innovation teams, as they sought to bring about healthcare innovation in the same hospital setting.

\section{METHODS}

\section{Study setting}

The research reported here formed part of a larger 'parent study' set within the public healthcare system of an Australian state jurisdiction. In this article, we focus on one of the partner hospital sites (hospital P) involved in the parent study. Details of the parent study are described in the previously published study protocol. ${ }^{6}$ Relevant details in the protocol ${ }^{6}$ and any protocol deviations have been addressed in this publication.

Hospital P comprised five individual hospitals and was the largest health service within the state providing approximately 1500 acute and subacute beds to a diverse and geographically dispersed community. As a teaching and research hospital, it engaged with the local university in numerous joint initiatives. These included translational research and innovation work conducted through a partnership with a research translation centre (henceforth 'the Centre'). This was colocated at hospital P's main site and enabled researchers, implementation experts and clinicians to collaborate on both internally and externally funded projects and other initiatives. Hospital P had also developed its own innovation function, which provided coaching, facilitation and project management expertise to front-line innovation interventions.

\section{Study design and methods}

We have undertaken comparative case study research that focuses on two examples of innovation teams delivering front-line interventions where the intention is to transform service delivery. Cases A and B teams undertook their innovation work at hospital $\mathrm{P}$ over 2 years.

The selection criteria for the case studied have been described in the parent study protocol. ${ }^{6}$ In summary, pragmatism guided case selection, to ensure that the case was likely to have sufficient longevity, feasibility of team access and of successful and timely research completion. Both cases involved potentially transformational change, in that one addressed mental health screening for a vulnerable refugee community, underscored by a national guideline concerning the delivery of mental healthcare in the perinatal period (case A), ${ }^{7}$ and the other involved the detection of delirium, which remains an intractable challenge for health services underpinned by the Australian National Accreditation Healthcare
Standards for 'best practice' (case B) ${ }^{8}$. Consistent with our interest in using IEP to better understand the role of those promoting transformational change, our research focused on the innovation teams rather than the target clinicians of their intervention. Table 1 provides details of each case, the interventions delivered, the innovation team delivering the intervention, the process and context of delivering the intervention.

The efforts undertaken by the innovation teams (in each case) were studied using a longitudinal qualitative study that applied a 'researcher in residence' as an ethnographic approach. ${ }^{9}$ This approach is used as an antidote to the traditional approach of separating the role of the researcher from the user of the knowledge created. ${ }^{9}$ This opportunity was afforded by AM and HJT's status as an in-service doctoral candidate supported by hospital $\mathrm{P}$ as part of their in-kind contribution to the parent project. Furthermore, through this approach, the researchers knew the cases and participants and were invited through this formal relationship to be involved in the research reported here. In both interventions, the innovation teams were open to enquiry and collaboration and to hosting a doctoral candidate in situ as a 'researcher in residence'.

\section{Patient and public involvement}

Participants from cases $\mathrm{A}$ and $\mathrm{B}$ provided consent to participate in this study. This involved face-to-face meetings with the researcher (AM) and a written explanatory document outlining the aims and intent of the research. Participants had the opportunity to ask the researcher further questions about the purpose and conduct of the research. Participants provided written consent after receiving this information. No patient involvement occurred in this study, hence patient consent was not attained.

\section{Data collection}

Qualitative data collection included ethnographic observations, semistructured interviews and findings from a document review. The document analysis enhanced understanding of policy, local contexts and processes that influenced each of the case studies and enabled 'openended inquiry' ${ }^{10-12}$ appropriate for the longitudinal study of innovation interventions as they unfold over time.

Data were collected over a period of approximately 24 months (January 2017 to December 2018). The timing of data collection for this research, relative to the case innovation work timelines, is illustrated in figure 1 .

Semistructured interviews (typically $30-60 \mathrm{~min}$ in length) were conducted with case team members and were recorded. Non-participant observation of the work being executed by the innovation teams as it developed and reached critical outcome milestones was also undertaken. Observation involved attending innovation team meetings which were recorded in field notes. Finally, a range of documentary evidence was accessed including internal hospital documents, meeting agendas, minutes 
Table 1 Characteristics of the innovation teams in case A and case B

\section{Case characteristics}

The intervention

Innovation team delivering the intervention

\section{Case A: implementing a mental health} screening tool

The intervention was underscored by a recommendation within a national evidence-based guideline concerning perinatal mental health screening with referral for follow-up management. ${ }^{7}$ The focus of the intervention was the integration of routine mental health screening into antenatal care for refugee women.

The intervention involved implementing a complex multidimensional perinatal mental health-status assessment using an online tool (translated into different languages for patient use) with follow-up services provided where appropriate. The outcomes of the application of the screening tool were then linked to a referral pathway in community care.

\section{Case B: improving screening for dementia and delirium}

The intervention was underpinned by the Australian National Accreditation Healthcare Standards for 'best practice' (National Safety and Quality Health Service Standards). ${ }^{8}$

The intervention aimed to embed screening into routine care intended to support patient-centred management strategies for acute episodes of dementia or delirium.

The intervention was complex and multidimensional and involved several elements including a delirium screening tool, a patient familiarisation tool, a patient-centred strategy aid to facilitate compassionate and effective care, an online clinician education course and intensive practical coaching for target clinicians from a cognition specialist. Implementation was based on the Confused Hospitalised Older Persons Program, ${ }^{18}$ with some local modification.

The innovation team was located and embedded within hospital $\mathrm{P}$ and comprised members of the innovation function (project officer and innovation facilitator), senior clinical service directors (medical and allied health directors), doctors (medical consultants from general medicine and geriatric), other specialists (cognition consultant, neuropsychologists, education specialists and communication experts) and nursing and management staff (nurse and service managers). up to $20 \%$ of all women in pregnancy during the first 12 months post birth with debilitating effects on women, children and families (deidentified published paper). In seeking to address this gap, Centre researchers partnered with clinicians within hospital $P$ and implementation and innovation experts to address the issue. In addition, extensive input was actively sought from diverse stakeholders including patients and community, academics, technical experts and clinicians.

The composition of the innovation team reflected this ethos with members with appropriate skills and expertise drawn from a clinical research background (senior research fellows, PhD scholars, front-line clinicians (nurse managers and midwives, maternal child health clinician, psychologist, service manager and obstetrician from service P) as well as a general practitioner. This crossdisciplinary team was managed through a governance framework that included all key internal and external stakeholders. 
Table 1 Continued

\section{Case characteristics}

IEP traits - subject position

Process and context of delivering the intervention
Case A: implementing a mental health screening tool

Peripheral position.

The targets for the innovation were clinical team managers and front-line clinicians delivering care in a perinatal setting within hospital P.

The trigger for the project was the lack of mental health screening undertaken in this setting, as per outlined as a recommendation within the national guideline and pervasive patient need. The delivery of the intervention was undertaken in one maternity clinic at one site.

From the outset, the refugee community was engaged by the innovation team and involved in the codesign of the intervention. This 'bottom-up' approach was also evident in the team's lateral approach to building support with departmental heads and target clinicians. Sustainability and scale-up was 'designed-in' from the beginning but not enacted until the intervention was proven effective in practice.

In general, the intended outcomes of the intervention were regarded by the team, project sponsors and stakeholders as being achieved.
Case B: improving screening for dementia and delirium

\section{Central position.}

The target clinicians for the innovation were clinical managers and front-line clinicians delivering care to patients at risk of developing delirium and/or dementia. They were located in a highly complex general medical and subacute setting across all sites of hospital P.

This intervention was triggered by a serious adverse event within hospital $P$ which drew attention to pervasive patient need and prompted a strong senior clinician desire to improve care practices. At the same time, an internal audit indicated that there were inconsistencies within hospital $\mathrm{P}$ between established national standards of care and clinical practice on the front line.

The intervention satisfied many of the 'critical success factors' associated with innovation initiatives. ${ }^{3}$ For example, strong support from the senior executive drove the innovation initiative which also provided a clear 'top-down' imprimatur which was maintained through active monitoring of progress from a senior level. Similarly, the intervention sought input from a wide range of stakeholders (eg, patients, academics, technical and educational experts and clinicians) who provided inputs in the development of the screening tool and during the implementation process. Implementation was carefully phased in three stages lasting 3 months across eight target wards. This enabled the innovation team to focus its resources on training and coaching staff, while daily and weekly evaluation allowed progress to be measured and learning to be captured to inform subsequent phases and assist the intervention to spread and scale.

Initially, internal reports and quality assurance data indicated strong outcomes from the intervention with early shifts in clinical practice and screening rates as the initial implementation phases were completed. However, by the time our research finished at the end of the third phase of implementation, the picture had changed. At this point, measures of intended outcomes after 18-24 months (eg, in terms of delirium and dementia risk screening rates and associated use of tools to improve patient-centred care) indicated a reduction in the use of tools and a decline in screening rates by target clinicians.

IEP, institutional entrepreneurship. 


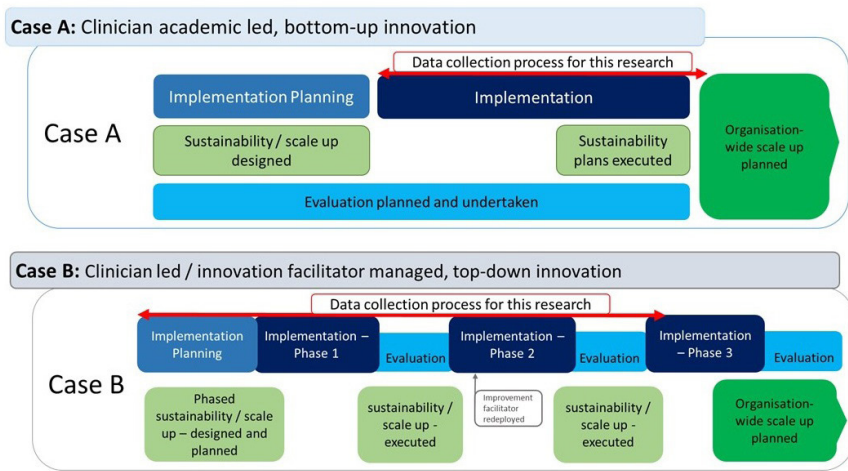

Figure 1 Depiction of the different processes adopted by the innovation teams within each case with overlay of data collection timeline for our research.

and presentations as well as published research outputs by the innovation teams stemming from their work. General concepts explored in the cases included constructs of leadership, context, process and content with the interview guide presented in online supplemental file 1 .

All innovation team members from both cases participated in interviews. In total, 47 interviews were conducted, 26 non-participant observations (team meetings) and 26 documentary sources were reviewed, refer to table 2 . The data from interviews were transcribed and along with field observations were managed using QSR NVivo V.12. ${ }^{13}$

The research team was a multidisciplinary team and all had extensive experience in health service research and qualitative methods.

\section{Analysis}

\section{Theoretical approach}

IEP is enacted by IEs who are key actors that can include organisations, groups of organisations, individuals or groups of individuals, "who leverage resources to create new or transform existing institutions'(Battilana et al, p68). ${ }^{3}$ The willingness of IEs to envision transformational change which challenges the status quo and their ability to enact this in practice is dependent on what institutional theory refers to as subject position. ${ }^{3}$ Broadly, this refers to the position occupied by a subject (individual, team, etc) within organisational and professional hierarchies and the interests, values and norms that this confers. As such, those in more peripheral subject positions (eg, health researchers, junior clinicians) are potentially more willing to envision new practices because they are less bound by organisational or professional norms and values and more likely to be influenced by external sources of new ideas. However, their ability to enact change is limited by their relatively marginal position in relation to sources of organisational power and professional standing. Conversely, IEs who occupy a more central subject position (eg, senior clinicians and service heads) are in principle better able to access such resources, as they possess more authority and status. However, their willingness to use such power to bring about transformational change may be limited because their proximity to

Table 2 Interviews and fieldwork undertaken for each case

\begin{tabular}{|c|c|c|}
\hline $\begin{array}{l}\text { Case study } \\
\text { participants }\end{array}$ & Interviews & Fieldwork observations \\
\hline \multicolumn{3}{|l|}{ Case A } \\
\hline $\begin{array}{l}\text { Project officer } \\
\text { (also PhD scholar, } \\
\text { midwife and } \\
\text { maternal child } \\
\text { health clinician) }\end{array}$ & 6 & $\begin{array}{l}\text { Implementation team } \\
\text { meetings: } 16 \\
\text { Documents examined: } 16\end{array}$ \\
\hline $\begin{array}{l}\text { Project officer (also } \\
\text { PhD scholar and } \\
\text { psychologist) }\end{array}$ & 2 & \\
\hline $\begin{array}{l}\text { Senior research } \\
\text { fellow (health } \\
\text { service research) }\end{array}$ & 2 & \\
\hline $\begin{array}{l}\text { Senior research } \\
\text { fellow and } \\
\text { obstetrician }\end{array}$ & 2 & \\
\hline $\begin{array}{l}\text { Senior research } \\
\text { fellow (psychology) }\end{array}$ & 1 & \\
\hline $\begin{array}{l}\text { Midwife-nurse } \\
\text { manager } 1\end{array}$ & 1 & \\
\hline $\begin{array}{l}\text { Midwife-nurse } \\
\text { manager } 2\end{array}$ & 1 & \\
\hline $\begin{array}{l}\text { General } \\
\text { practitioner }\end{array}$ & 1 & \\
\hline Service manager & 1 & \\
\hline $\begin{array}{l}\text { Senior research } \\
\text { fellow and midwife }\end{array}$ & 1 & \\
\hline Total & 18 & \\
\hline
\end{tabular}

\section{Case B}

Innovation

6

facilitator/project

officer

Cognition

consultant (allied

health specialist)

Nurse manager 12

Nurse manager $2 \quad 1$

Medical consultant 3

(general medicine,

$\mathrm{n}=2$ )

Medical consultant 2

1 (geriatric)

Medical consultant 1

2 (geriatric)

Service manager

Education 1

specialist

Total 29

existing structures of organisational and/or professional jurisdiction means that they view innovation as a means of improving the status quo rather than transforming the 
system. ${ }^{1}$ Ideally, those charged with transformation would occupy intermediate subject positions which would equip them with the power to lead and facilitate change because the willingness and vision to bring about change could be combined with an ability to enact it in practice. ${ }^{1}$

However, whatever the power invested in IEs by virtue of their subject position, its exercise has to be seen as legitimate by others if they are to access the various resources (eg, knowledge or expertise, networking and relational capabilities, finance and funding) required to undertake innovation and to foster engagement and build trust with stakeholders. There are two important sources of legitimacy. First, structural legitimacy bestowed through formal institutional arrangements and invested in IEs to sanction their access to the resources necessary to preserve or change existing arrangements. Second, normative (or moral) legitimacy which confers a commitment or willingness to inspire or convince others, by building connections and relationships because it is 'the right thing to do' (Battilana et al, p575). ${ }^{3}$

We used the interview and observation data to capture how the subject position of an IE (the innovation teams) influenced their ability to access and use resources (to build structural legitimacy) and inspire and engage others (to develop normative legitimacy) to enact change. Themes associated with the IE concepts were analysed progressively, until saturation was reached. Analysis was grounded and inductive, influenced by aspects of implementation, institutional theory and improvement science. Broad themes were elicited through an opencoding process. ${ }^{14}$

Regular meetings between the research team members (all authors) facilitated critical exploration of participant responses and observations and agreement on emerging themes and concepts throughout the analysis.

\section{RESULTS}

The characteristics of the interventions, how each case unfolded and the outcomes achieved are presented in table 1. We now use the lens provided by IEP to explore the subject positions of each of the innovation teams and

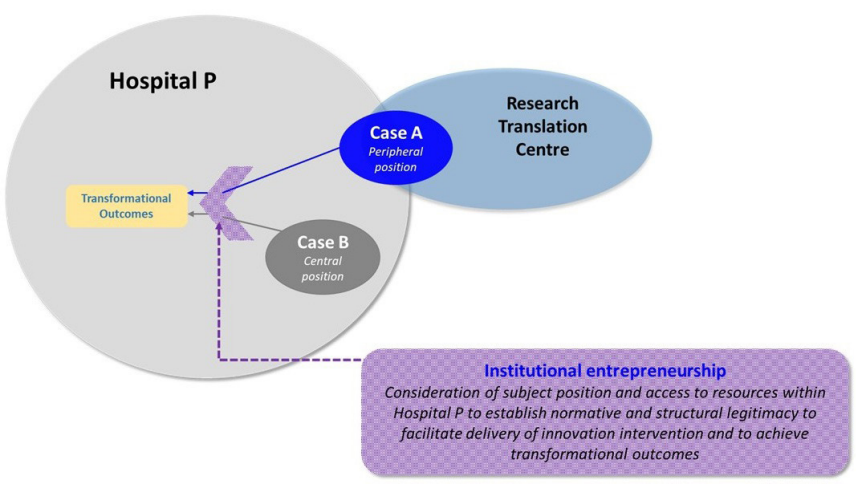

Figure 2 Exploration of institutional entrepreneurship concepts through the case studies. the nature of the legitimacy afforded to them, figure 2 illustrates the exploration of IEP concepts.

\section{Case A: peripheral subject position and the quest for structural legitimacy}

Case A aimed to implement mental health screening and service integration for antenatal care of refugee women. The innovation team in case A occupied a peripheral subject position. The Centre and its incumbents were one step removed from hospital P's organisational hierarchy and associated professional service silos. Unsurprisingly, working within and through the Centre, innovation team members exhibited a strong willingness to improve healthcare delivery on the front line, especially as in this instance where the recipients of care were a disadvantaged and vulnerable group.

The national guidelines are for every woman. We decided to start with refugee women, acknowledging that it was a high-risk population and yep, probably where the greatest unmet need was. Of course it was also the most complex population which is one of the reasons why it hasn't been done. Senior research fellow (health service research)

Notwithstanding this willingness, the Centre's armslength relationship to the organisational and clinical systems and structures in hospital P might be expected to have rendered the novel innovation difficult to implement and sustain, either because of a lack of senior management and/or clinical support or because of the difficulty in engaging front-line clinical staff. However, the team was able to bring about a successful and sustainable innovation, in large part, by building both relationships that gave them the power to access the resources necessary and ensuring they had the authority to use these resources.

For example, a concerted attempt was made by the innovation team to gain the support of the hospital $\mathrm{P}$ executive that, once secured, was successfully maintained but remained at a distance. The innovation team similarly worked to gain and maintain the support of local leaders involved in the delivery of the maternity and refugee services within hospital P. The team sought to maintain these relationships through the course of the intervention via regular updates and dialogue but without inviting direct day to day involvement.

I think we needed to have the okay from [Director of Obstetrics] in beginning or we couldn't do it. I did contact the director of obstetrics at [site]. [x] was happy for us to go ahead and do whatever we wanted, [x] didn't really feel the need to be involved. Senior research fellow and obstetrician

Overall a 'bottom-up' approach combined with effective 'managing-up' to gain and maintain executive and departmental support, ensured a power base from which to secure vital access to key resources such as funds for the project, the development of the intervention 
tools and commitments of target clinician time during implementation.

The peripheral position of the team was also addressed through building strong lateral and partnership relationships with target clinicians. As team members observed, this proved important in engaging local champions and involving others in the intervention.

We spoke to settlement services, community members, the managers and staff I worked with at the community health centre, because you want to look at where you're going to get your referrals from. People need to know about the service, they need to know what's happening and how it's going to be implemented. Feel that they're actually a part of the process. Project officer

By these means, the innovation teams were able to ensure that their willingness to effect change was not undermined by a lack of power to access resources to get things done from an ostensibly peripheral subject position. However, this team potentially also lacked the authority to use this power legitimately. Again, our findings suggest a number of mitigating factors served to address this potential deficit.

In relation to structural legitimacy or the authority invested in them to undertake the intervention, the teams were able to draw on the professional standing of its members, conferred through the academic and professional credentials and their status in academic and professional communities. This gave them particular authority in relation to expertise and understanding of the health issues of patients and efficacy of interventions to address them. Further, the arms-length approval gained from the executive and bottom-up approach to managing innovation combined to provide an effective justification for efforts aimed at inclusion, networking, negotiating, relationship building and connection development with key stakeholders. Finally, members of the innovation team exercised their expertise in ways that bolstered their invested authority using 'diplomacy', emotional intelligence and high-level communication skills to inspire stakeholders and adopters to use opportunities to codesign, discuss, adapt, modify and shape the innovation work according to their ability and context.

These efforts, in the view of the innovation team at least, served to build trust and acceptance among clinicians targeted by the intervention.

It's about understanding how systems work and making sure that you're actually engaging with every person that's part of that system. Senior research fellow (psychology)

In terms of normative legitimacy, or the willingness of others to accept their arguments concerning the need for change because it is the right thing to do. The team's approach was bolstered by the design, implementation and evaluation of the intervention using an established, evidenced and well-theorised framework (normalization process theory). ${ }^{15}$ This framework provided established methods and resources to embed the intervention into routine practice by changing clinician behaviours and beliefs. This involved undertaking in-depth formative patient needs assessment and embarking on efforts to build clinician engagement before development of the innovation work began and taking a structured approach to measuring changes in clinical practice and patient outcomes to provide target clinicians with evidence of the ongoing impacts of the intervention.

So the chances of being able to roll it out across all of the Maternity Service would be great if we could get it to work in this most challenging circumstance. If we can demonstrate that it works in this situation then there can be very little criticism or very little but what if? There are very few excuses that can come up that we have not already seen and addressed. Senior research fellow (health service research).

At the same time, the early and in-depth engagement with patients and the refugee community provided strong narratives concerning unmet patient needs which were highly persuasive in winning the 'hearts' and 'minds' of target clinicians and other key stakeholders.

The main driver was that it was a very high-risk population and we were concerned about that gap and care for them. As we went through we started talking to more and more people, we met more people, and so because it started with me, my $\mathrm{PhD}$ supervisor, so both researchers and she's an obstetrician and gynaecologist as well, and the head of midwifery and the operations manager for the Refugee Health and Wellbeing Service. Senior research fellow (health service research)

Before we even did the formative research, the important thing was we knew we needed to speak to community members. If we can get it right in this setting [refugee, maternal health services], it should be easier to establish it in a less challenging setting of a general maternity setting. Senior research fellow (psychology)

\section{Case B: central subject position and the struggle to maintain normative legitimacy}

Case B aimed to embed screening into routine care intended to support patient-centred management strategies for acute episodes of dementia or delirium. The subject position of the case B innovation team, relatively speaking at least, reflected a more central subject position in relation to organisation and professional jurisdiction within hospital P. First, the innovation team assembled was drawn entirely from within the service. Second, several team members occupied senior clinical or management roles, while innovation and project management expertise was provided by a senior member of hospital P's innovation function along with a clinical specialist in cognition. Third, the team had been assembled as an 
internal response to an external audit and an adverse event. Tasked by the hospital executive with the strong public support of the chief executive, it also received sponsorship from senior directors of medical and allied health services.

Consistent with this subject position, the team developed a response to the lack of front-line clinician adherence to national standards, which would have the least impact on current clinical practice. To some degree such a response was invited by the standards themselves which set out a prescribed expectation about the 'best practice' for patients. These requirements were not transformative but rather defined the minimum national standards of safe and quality care. ${ }^{15}$ As such, the standards could be interpreted as requiring relatively conservative changes to clinical practice in order to ensure the minimum requirements were met.

Thus, the aim of case B demonstrated high value for patients, it required low-to-moderate effort for clinicians. This had the merit of meeting an urgent requirement to meet minimum external standards in an effective way. However, it was not a transformative solution in the same way that, say, a program to redesign and renovate wards so that they were more dementia friendly provides (an example of the other options initially considered but ultimately deprioritised by the team), which might have been driven by an ambition to do more than just meet minimum requirements.

Similarly, the central subject position enjoyed by the team meant they were able to use the power of the 'topdown' benefits of executive imprimatur and the professional standing of team members to bring about and make the necessary changes. The team was able to mobilise the necessary organisational and governance resources (eg, access to additional expertise to develop training resources, data managers to enable analytics for evaluation purposes) and chose to implement a framework that clinical peers in comparable settings had already applied elsewhere (hence the team's mantra was that 'if it works elsewhere, it can be made to work here').

The subject position of the innovation team and by virtue of this the intervention itself were therefore invested in significant structural legitimacy, which would suggest that the ability to bring about the necessary changes in clinical practice was not an issue. It was assumed that the required changes to front-line practice on the wards would readily scale and spread as local 'champions' provided 'leadership from within' and 'champion' are the causes.

However, (see table 2), while enjoying initial success in terms of clinical take up and use, as the implementation progressed use of the screening tool and its impact started to fall away. What appeared to be at stake here was the normative legitimacy associated with the innovation and in particular the extent to which target clinicians were persuaded that there was both a need for change and that this was the right thing to do.

One indicator of the problems encountered is provided by the experience of those members of the innovation team (an innovation facilitator and a cognition consultant) charged with implementation and clinician engagement. Their work served in significant ways to build and maintain the normative legitimacy of the intervention and to ensure that target clinicians were engaged and adopted the new screening tool in their day-to-day practice. As the innovation facilitator put it, 'It's very much about the clinicians having to lead their clinical projects... and we're there to back them up'.

Accordingly, the Innovation facilitator worked hard to engage clinicians, leverage relationships and network with key champions across hospital $\mathrm{P}$. This involved such activities as consulting within the innovation team about prioritisation of directions to adopt to address the practice gaps, seeking clinician participant perspectives about the proposed implementation process and potential barriers and enablers and negotiating with target wards about appropriate timing for inclusion in the phased implementation.

A critical juncture in the process of innovation and implementation occurred when the innovation facilitator was redeployed from the case B to deal with other, more urgent, innovation priorities, requiring facilitation elsewhere in hospital P. This meant the innovation team was short of vital expertise to facilitate, guide and manage the implementation of routine screening during its later phases. In turn, this weakened the team's capacity to maintain the carefully constructed and previously successful engagement and connection with target frontline clinicians.

While the innovation facilitator's responsibilities were reassigned to other team members, this did not, as they recognised, necessarily play to their strengths. An ensuing decline in capacity to undertake engagement was reported in our interviews. This meant that there was now inadequate time to undertake the important activities of coaching and engagement with front-line clinical teams.

When [Innovation facilitator] left we lost the support from innovation which is frustrating. Doing the preimplementation stuff whilst still being on, present on the wards here then trying to organise the education sessions for the three months with the nurse educators, that's been probably a struggle. Cognition consultant

The redeployment also diminished the team's capacity to further develop relationships and network with champions across hospital $\mathrm{P}$ in order to ensure the further spread and scale of the intervention.

In sum, it could be suggested that an unintended consequence of the redeployment of the Innovation facilitator was that it contributed to weakened normative legitimacy for the project. In reality, this meant clinicians simply stopped adhering to new practices, as they were not so easily persuaded to take them up because they were not convinced of the need or that the practices were the right thing to do. 
Table 3 Themes illustrating legitimacy

\begin{tabular}{|c|c|c|}
\hline & Case A & Case B \\
\hline Subject position & Peripheral & Central \\
\hline \multicolumn{3}{|l|}{ Structural legitimacy } \\
\hline $\begin{array}{l}\text { Multidisciplinary improvement team embedded within hospital P: } \\
\text { authority in relation to expertise and understanding of context }\end{array}$ & $\checkmark$ & $\checkmark$ \\
\hline \multicolumn{3}{|l|}{ Normative legitimacy } \\
\hline $\begin{array}{l}\text { Implementation of established knowledge (evidence and standards: } \\
\text { establishes a legitimacy of 'need' and 'moral' basis for changing } \\
\text { practices) }\end{array}$ & $\checkmark$ & $\checkmark$ \\
\hline Patient involvement and engagement & $\checkmark$ & $\begin{array}{l}\text { X } \\
\text { Indirectly through representatives }\end{array}$ \\
\hline Improvement outcomes & $\begin{array}{l}\text { Achieved positive } \\
\text { changes }\end{array}$ & $\begin{array}{l}\text { Achieved time limited positive } \\
\text { changes }\end{array}$ \\
\hline
\end{tabular}

We summarise the different types of legitimacy and our observations reported for each case in table 3. This provides the coding tree applied to the data, elicited through an open-coding process. ${ }^{14}$

\section{DISCUSSION}

Lockett et al (2012) ${ }^{6}$ suggests that innovation work is most likely to be transformative where those leading change occupy intermediate subject positions. However, our findings suggest that this does not mean that innovation teams in more peripheral or central subject positions cannot bring significant change about. As we have seen, those in more peripheral subject positions can do things that mitigate deficiencies in structural legitimacy which might otherwise confound a strong normative commitment to transformation. Conversely, while those in more central subject positions are likely to achieve more when the changes proposed tend towards conservative rather than transformational changes, even here the need to build and maintain normative legitimacy is key to achieving sustainability.

The innovation team in case A sought to implement the mental health screening tool from a peripheral subject position. While this might be expected to undermine their efforts, the observed outcomes revealed broad acceptance and take up of the intervention. In contrast, the innovation team in case B occupied a central subject position and worked toward implementing an intervention to identify and manage patients with delirium. This position might be expected to enable them to implement service innovations but to be only willing to do this in relatively conservative ways.

Despite the challenges of being in a peripheral subject position, case A team found effective ways of building the necessary structural legitimacy to ensure that they were not only willing but also able to implement the intervention.

In contrast while the innovation team in case B leveraged their central subject position and achieved improvements that began to spread across the target wards, this momentum, as evidenced by the team's own outcome measures, was not sustained. Notably, case B did not engage to the same degree with patients and community compared with case A, which was as a key driver of normative legitimacy. This may have further diminished normative motivation for improvements.

While offering considerable strengths in terms of contextual insight and access to emerging and unfolding processes as they happen, the 'researcher in residence' approach also brings potential limitations. Particularly, the issue that some participants were known to the primary researcher, and vice versa, and that her formal position within the organisation could be a source of both influence and bias during data collection and analysis. It is also possible that her position may have limited what it is possible to discuss because of more acute issues concerning anonymity and confidentiality. ${ }^{16}$ These potential problems of maintaining appropriate 'distance' were mitigated by the nesting of the study within the parent project which enabled other researchers not associated 
with hospital P to engage with and reflect on the data and its interpretation.

\section{CONCLUSION}

The factors that affect the willingness and ability of innovation teams to bring about transformational change were investigated through the roles and actions of two front-line IE innovation teams, as they sought to bring about healthcare innovation in the same hospital setting. Through the lens of IEP and innovation case studies, we have extracted new and valuable perspectives on improving healthcare innovation. ${ }^{17}$ We have sought to move beyond the focus of previous research ${ }^{12}$ on IEs as individuals, to understand these factors relevant to innovation teams. We have shown these factors are manifested through the manner in which innovation teams operating from different subject positions are able to influence the structural and normative legitimacy afforded to their activities. Power (organisational or professional) to bring about transformational change does not necessarily translate to willingness for change and those most invested in change may not have the influence to deliver it. This offers practical insights on how better to support innovation teams in driving change that integrates knowledge from research, clinical perspectives and patient experience to enable interventions to spread and scale.

Acknowledgements The authors acknowledge the contribution from Dr Prue Burns for her insights with respect to application of theory, methodology and conceptual contribution associated with the theoretical analysis. The authors also acknowledge the generous contribution of participants of this study.

Contributors AM: Conceptualisation, methodology, formal analysis, investigation and cowriting (original draft, review and editing). IM: Conceptualisation and methodology, investigation and cowriting (original draft, review and editing). HJT: Conceptualisation and methodology, investigation and cowriting (original draft, review and editing). TR: Participated in investigation and analysis and cowriting (review and editing). Rl: Contributed to investigation and analysis and cowriting (review and editing). IM, HJT, TR and RI: Provided oversight and leadership responsibility for the research activity planning and execution, including mentorship to AM.

Funding The research was supported through the parent study, funded by the Australian Research Council (LP140100243), and in kind support from the partnering health service participating in the research.

Competing interests None declared.

Patient consent for publication Not required.

Ethics approval The study was reviewed and approved by hospital P's ethical review committee (Reference LNR/16/MonH/259).

Provenance and peer review Not commissioned; externally peer reviewed.

Data availability statement Data are available upon reasonable request.

Supplemental material This content has been supplied by the author(s). It has not been vetted by BMJ Publishing Group Limited (BMJ) and may not have been peer-reviewed. Any opinions or recommendations discussed are solely those of the author(s) and are not endorsed by BMJ. BMJ disclaims all liability and responsibility arising from any reliance placed on the content. Where the content includes any translated material, BMJ does not warrant the accuracy and reliability of the translations (including but not limited to local regulations, clinical guidelines, terminology, drug names and drug dosages), and is not responsible for any error and/or omissions arising from translation and adaptation or otherwise.

Open access This is an open access article distributed in accordance with the Creative Commons Attribution Non Commercial (CC BY-NC 4.0) license, which permits others to distribute, remix, adapt, build upon this work non-commercially, and license their derivative works on different terms, provided the original work is properly cited, appropriate credit is given, any changes made indicated, and the use is non-commercial. See: http://creativecommons.org/licenses/by-nc/4.0/.

ORCID iDs

Angela Melder http://orcid.org/0000-0003-3942-5543

Rick ledema http://orcid.org/0000-0001-6792-1048

\section{REFERENCES}

1 Lockett A, Currie G, Waring J, et al. The role of institutional entrepreneurs in reforming healthcare. Soc Sci Med 2012;74:356-63.

2 Lockett A, El Enany N, Currie G, et al. A formative evaluation of collaboration for leadership in applied health research and care (CLAHRC): institutional entrepreneurship for service innovation. 2014;2:1-124.

3 Battilana J, Leca B, Boxenbaum E. 2 How Actors Change Institutions: Towards a Theory of Institutional Entrepreneurship. Acad Manag Ann 2009;3:65-107.

4 Suchman MC. Managing legitimacy: strategic and institutional approaches. Acad Manage Rev 1995;20:571-610.

5 Eriksson N, Ujvari S. Fiery spirits in the context of institutional entrepreneurship in Swedish healthcare. J Health Organ Manag 2015;29:515-31.

6 Melder A, Burns P, Mcloughlin I, et al. Examining 'institutional entrepreneurship' in healthcare redesign and improvement through comparative case study research: a study protocol. BMJ Open 2018;8:e020807.

7 Austin M-P, Highet N, the Expert Working Group. Mental health care in the perinatal period: Australian clinical practice guideline. Melbourne: Centre of Perinatal Excellence, 2017.

8 National Safety and Quality Health Service Standards. 2017 second edition Australian Commission. Available: https://www. safetyandquality.gov.au/standards/nsqhs-standards/recognisingand-responding-acute-deterioration-standard [Accessed 29 Jul 2020].

9 Marshall M, Pagel C, French C, et al. Moving improvement research closer to practice: the Researcher-in-Residence model. BMJ Qual Saf 2014;23:801-5.

10 Crowe S, Cresswell K, Robertson A, et al. The case study approach. BMC Med Res Methodol 2011;11:100.

11 Edmondson AC, Mcmanus SE. Methodological fit in management field research. Acad Manage Rev 2007;32:1246-64.

12 Tumilowicz A, Neufeld LM, Pelto GH. Using ethnography in implementation research to improve nutrition interventions in populations. Matern Child Nutr 2015;11 Suppl 3:55-72.

13 QSR International Pty Ltd. NVivo qualitative data analysis software. version 12, 2018.

14 Strauss A, Corbin J. Basics of qualitative research. Thousand Oaks, California: Sage Publications, Inc, 1990.

15 May C, Finch T. Implementing, embedding, and integrating practices: an outline of normalization process theory. Sociology 2009;43:535-54.

16 Kaiser K. Protecting respondent confidentiality in qualitative research. Qual Health Res 2009;19:1632-41.

17 Dixon-Woods M, Mary D-W. How to improve healthcare improvement-an essay by Mary Dixon-Woods. BMJ 2019;367:I5514.

18 NSW Agency for Clinical Innovation and the NHMRC Cognitive Decline Partnership Centre. Care of confused hospitalised older persons (chops) program. Available: https://www.aci.health.nsw.gov. au/chops [Accessed 17 Jul 2020].

19 Robinson T, Skouteris H, Burns P, et al. Flipping the paradigm: a qualitative exploration of research translation centres in the United Kingdom and Australia. Health Res Policy Syst 2020;18:111. 